\title{
A tamper-proof fluid dispenser and drinkometer for monkeys'
}

JACK H. MENDELSON AND NANCY K. MELLO

STANLEY COBB LABORATORIES, MASSACHUSETTS GENERAL HOSPITAL AND HARVARD MEDICAL SCHOOL

\begin{abstract}
A fluid dispensing system for primates is described that yields reliable and accurate measures of fluid consumption. Since fluid can be obtained only by licking and not by sucking, the device can be attached to a standard drinkometer sensing circuit.
\end{abstract}

\section{Problem}

Prerequisite to any study involving drinking behavior in monkeys is the development of a tamper-proof fluid dispenser which permits accurate measurement of the total volume of fluid consumed over a specified period of time. In addition to measuring the total volume of fluid consumed, it is often valuable to observe when, and in what pattern, a monkey drinks. The drinkometer introduced by Stellar \& Hill (1952) is a convenient device for study of the temporal pattern of drinking. A drinkometer sensing circuit detects each contact (i.e. lick) on a fluid tube and each discrete lick can be recorded on a cumulative recorder as a function of time. Several studies (Stellar \& Hill, 1952; Teitelbaum $\&$ Derks, 1958) have shown a correlation between licking and volume of fluid consumed in the rat.

The leak-proof fluid dispensing systems previously described for monkeys require sucking to obtain fluid (Grunzke \& Rohles 1963; Povar \& Salk, 1965). The amount of fluid that can be obtained as a function of the duration and force of sucking is somewhat more variable than the amount of fluid that can be obtained by licking. It was anticipated that if a standard drinkometer were used to detect the onset of a sucking response by a monkey, it would be difficult to correlate volume of fluid consumed with rate of sucking. Whereas if it were possible to require a monkey to lick, each discrete lick would yield a comparable volume of fluid and rate of drinking could be examined with a standard drinkometer circuit and a cumulative recorder.

\section{Apparatus}

The tamper-proof liquid drinkometer devised for monkeys is shown in Fig. 1. The device consists of a $1200 \mathrm{ml}$ stainless steel cannister ${ }^{2}$ to which are attached: a glass gauge calibrated to indicate the fluid volume in the cannister (Fig. 1, left) and a pressure regulating tube of $4 \mathrm{~mm}$ inside diameter which opens into the cannister at exactly the same level as the output aperture (Fig. 1, right). Once the cannister is sealed with a rubber stopper, the pressure regulating tube allows air to enter when fluid is consumed. The contents of the cannister are always under one atmosphere of pressure. Consequently fluid can be licked from the outflow tube with ease but no fluid will drip or leak from the cannister when it is jarred or shaken. This device permits recording the total volume of fluid consumed by a monkey for a specified period of time.

Since a drinkometer device requires discrete licks to provide pulses to the recording circuitry, it was necessary to devise a system where only licking and not sucking could occur. A double ring of plexiglas was cemented to the end of the stainless steel tube. The two rings of plexiglas were separated by a distance of $3 \mathrm{~mm}$. The tip of the outlet tube was placed in close approximation to the inner plexiglas ring. In order to obtain fluid, the monkey had to protrude its tongue through the outer plexiglas ring and lick the tip of the outlet tube. It is impossible for the animal to suck fluid with this arrangement because of the open space between the inner and outer plexiglas rings. The temporal pattern of drinking could be observed by attaching an electronic sensing unit (i.e.a drinkometer) to the liquid dispenser.

\section{Results}

Typical cumulative records of the drinking patterns of a rhesus monkey are shown in Fig. 2. The monkey was maintained in a restraining chair and the fluid tube of the drinkometer was placed close to the monkey's head. The chair was arranged so that the monkey's hands could not reach the drinkometer. Each lick on the metal fluid tube was detected by the electronic sensing device which was attached both to the fluid dispenser and the metal seat of the restraining chair. These data show that a high rate of licking yielded less fluid than in intermediate or low rate.

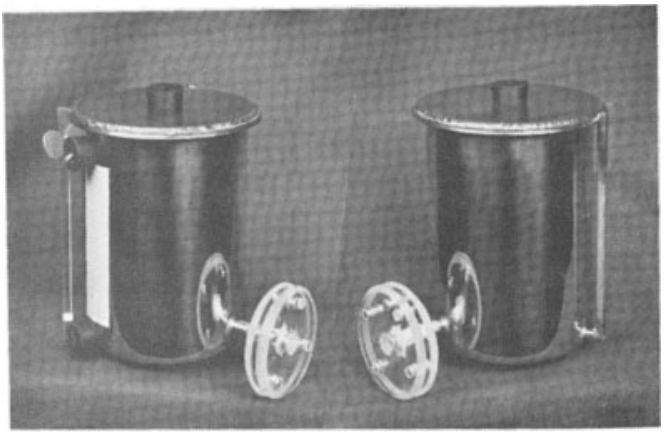

Fig. 1. A tamper-proof drinkometer for monkeys. A calibrated glass guage to indicate total fluid volume is shown on the left. An air pressure regulating tube is shown on the right. 

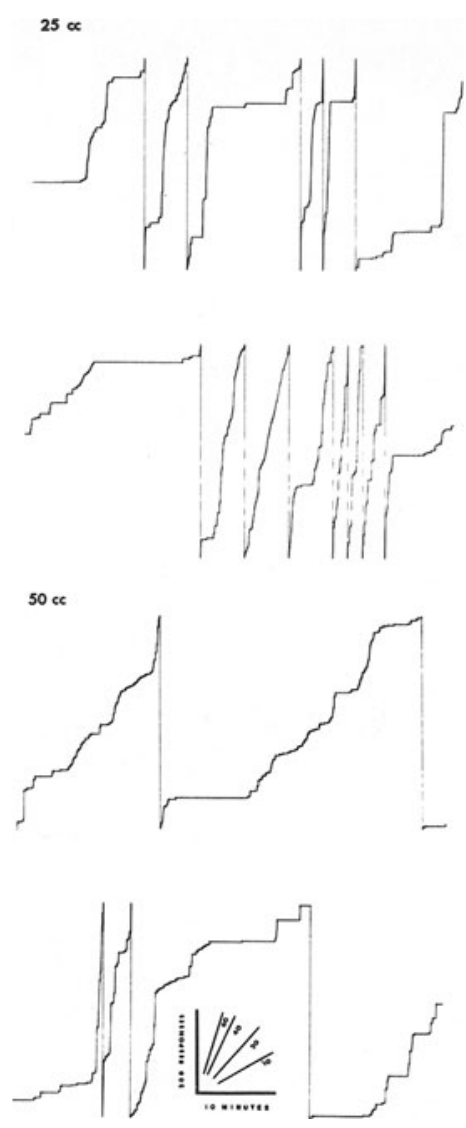

Fig. 2. Cumulative records of licking responses from the tamperproof drinkometer by a rhesus monkey.

\section{Diseussion}

It should be noted that two devices have been described that permit recording drinking behavior which is defined in terms of sucking. Grunzke (1961) has reported a sucking device for primates that delivers a constant volume of fluid per suck. Kron and his associates (1963) describe a sucking device for infants which dispenses an amount of fluid proportional to sucking pressure. Sucking pressure in turn is continuously measured with a pressure transducer and graphic recorder

One advantage of a drinkometer or a suckometer is that an animals' instrumental response (e.g. a lick) is identical to its consumatory response. Following the introduction of the drinkometer by Stellar \& Hill (1952), Williams \& Teitelbaum (1956) showed that the device could be used to force rats to drink large amounts of fluid by making avoidance of a noxious shock contingent upon drinking. Each response (i.e. lick on the tube) operated a cumulative recorder and a controlling circuit which programmed the conditions of reinforcement. The basic datum is the animal's rate of response and this technique provides a continuous account of the animal's drinking behavior as a cumulative record. This device has been used in combination with avoidance schedule (Teitelbaum \& Derks, 1958) and schedules of positive reinforcement (Premack et al, 1964). It has recently been shown that the rate of drinking on a drinkometer can be specified by the schedule of reinforcement used (Mello \& Mendelson, 1965).

\section{References}

Grunzke, M. E. A liquid dispenser for primates. J. exp. Anal. Behav ., 1961, 4, 326.

Grunzke, M. S., \& Rohles, F. H. Ad lib water dispensing. Lab. primate Newsltr., 1963, 2 (\#1) 8.

Kron, R. E., Stein, M., \& Goddard, K. E. A method of measuring sucking behavior of newborn infants. Psychosom. Med., 1963, 25, 181-191.

Mello, N. K., \& Mendelson, J. H. Operant drinking of alcohol on a rate contingent ratio schedule of reinforcement, J. psych. Res., in press.

Povar, M. L., \& Salk, R. A device for measuring fluid intake by primates, J. exp. Anal Behav., 1965, 8, 187-188.

Premack, D., Schaeffer, R. W., \& Hondt, A. Reinforcement of drinking by running: Effect of fixed ratio and reinforcement time. J. exp. Anal. Behav., 1964, 7, 91-96.

Stellar, E., \& Hill, J. H. The rats rate of drinking as a function of water deprivation. J. comp. physiol. Psychol., 1952, 45, 96-102.

Teitelbaum, P., \& Derks, P. The effect of amphetamine on forced drinking in the rat. J. comp. physiol. Psychol., 1958, 51, 801-810.

Williams, D. R., \& Teitelbaum, P. Control of drinking penavior by means of an operant conditioning technique. Science, 1956, $124,1294-1296$.

\section{Notes}

1. This study was supported in part by research Grants $M H$ 0843201 and MH 05619-04 from the National Institute of Mental Health. 2. The stainless steel cannister with the appropriate apertures and a pressure regulating tube is available from the J. F. Bingham Mfg. Co. Lawrence, Massachusetts. Calibrations and attachments of the plexiglas rings were done in our laboratory.

3. Drinkometer model E 110M. Grason-Stadler Co. West Concord, Mass. 